\title{
Effect of implementing designed educational training program for neurological nurses on clinical outcomes of stroke patients
}

\author{
Seham A. Abd El-Hay*1, Amany K. Abed Allah ${ }^{1}$, El Sayed A. Tag El Din ${ }^{2}$ \\ ${ }^{1}$ Medical \& Surgical Nursing Department, Faculty of Nursing, Tanta University, Egypt \\ ${ }^{2}$ Neuropsychiatry Department, Faculty of Medicine, Tanta University, Egypt
}

Received: October 15, 2018

Accepted: November 23, 2018

Online Published: November 30, 2018

DOI: $10.5430 / \mathrm{cns} . v 6 \mathrm{n} 4 \mathrm{p} 121$

URL: https://doi.org/10.5430/cns.v6n4p121

\begin{abstract}
Background: Stroke is a major cause of functional disability, it increased the need for continuous nursing care. Nurses need to pay attention not only to the physical recovery after stroke, but also to the psychological and social recovery. Therefore, it is important to provide training courses to nurses about care of stroke patients.

Aim: This study was conducted to evaluate the effect of implementing designed educational training program for neurological nurses on clinical outcomes of stroke patients.

Methods: Design: A quasi experimental research design was utilized. Setting: Data were collected from Neurological Intensive Care Units, Wards and Neurological outpatient clinics of Tanta Main University Hospital. Sample: All nurses $(\mathrm{n}=35)$ who are providing direct care for stroke patients and a purposive sample of 30 stroke patients. Tools: Three tools were used to collect data. Tool (I): Assessment of nurses' knowledge questionnaire sheet about stroke; Tool (II): Observational checklist to evaluate nurses' practice regarding care of stroke patients; and Tool (III): Patient's clinical outcomes assessment sheet.

Results: The results revealed that there were significant improvements in nurses' knowledge and practice regarding care of stroke patients post training program at $p<.01$. Also, significant improvements in self-care and activities of daily living among stroke patients were observed from immediately to 2 months later post application of training program.

Conclusions: The study findings revealed that the implementation of designed educational training program within 2 months were successful for improving nurses' knowledge and practice regarding care of stroke patients. Furthermore, there was improvement in activities of daily living and self-care among stroke patients.

Recommendations: It is recommended to generalize implementation of designed educational training program for neurological nurses as a routine hospital care for stroke patients.
\end{abstract}

Key Words: Stroke, Educational training program, Neurological nurses, Clinical outcomes

\section{INTRODUCTION}

Stroke is a clinical syndrome that is characterized with rapidly developing of functional disability and it is the mainleading cause of death worldwide. ${ }^{[1]}$ World Health Organi- zation 2017 revealed that between $20 \%$ to $50 \%$ of people that are suffering from a stroke may be exposed to death depending on the severity of the stroke, age of the patient, and effectiveness of management. ${ }^{[2]}$ In Egypt WHO estimated

\footnotetext{
*Correspondence: Seham A. Abd El-Hay; Email: drsehamahmed@yahoo.com; Address: Medical \& Surgical Nursing Department, Faculty of Nursing, Tanta University, Egypt.
} 
that a large number of new strokes were around 150,000 to 210,000 events that occured per year and about $85 \%$ of stroke deaths occured in low and middle-income countries such as Egypt. ${ }^{[3]}$ Stroke is the leading cause of long-term functional disability where $50 \%$ to $70 \%$ are functionally independent and $15 \%$ to $30 \%$ live with permanent disability. ${ }^{[4]}$ In addition, $32 \%$ will use home healthcare services and $26 \%$ require long-term care. ${ }^{[5]}$

Stroke or "brain attack", is defined by the WHO as a "neurological deficit of cerebrovascular cause that persists beyond 24 hours or is interrupted by death within 24 hours". ${ }^{[6]}$ More than three quarter of strokes are ischemic (interruption of the blood supply to the brain), and the remaining $20 \%$ are hemorrhagic (due to rupture of a blood vessel). ${ }^{[7,8]}$ Stroke occurs due to the following risk factors: overweight, aged 55 years or older, a personal history of stroke, an inactive lifestyle and a tendency to drink alcohol, smoke. ${ }^{[9,10]}$ The symptoms of stroke includes; weakness of limb, sensory deficits, aphasia, dysphagia, visual field deficit, coordination problems and cognitive impairment. ${ }^{[11]}$ Furthermore, depression, and lower physical activity are common symptoms in stroke survivors. ${ }^{[12,13]}$ Treatment must be started directly after the diagnosis of a stroke, because immediate medical treatment is crucial to decrease disability and the risk of death. ${ }^{[14]}$

Ischemic or hemorrhagic stroke leads to long-term functional disability for about $50 \%$ to $70 \%$ and cognitive deficits that are ranged from mild to severe disability, so stroke patients require specfic nursing care to improve patients' quality of life and functional progress. ${ }^{[4,15]}$ Because neuorological nurses play a vital role during care of the stroke patients and prevention of current and future complications particularly as nurses are responsible for patients' 24-hours care per day. So, it is necessary to create training program for nurses regarding care of patients who had suffered from a stroke based on updated scientific manner and evidence based practice to overcome motor impairment and cognitive deficit. ${ }^{[16,17]}$ Nursing care for stroke patients must focus on aiding in functional recovery, assisting in self-care and activities of daily living, reducing the risk of secondary complications and finally, promoting holistic adaptation to stroke related disability. ${ }^{[18,19]}$

Educational training program for nurses during care of stroke patients aimed to improve knowledge and practice regarding appropriate intervention, minimize the devastating effects of stroke and prepare patients for rehabilitation phase. ${ }^{[20]}$ Nursing care for stroke patients is arranged, based on several priorities to ensure optimal patient outcomes. Afirst priority during intervention is stabilisation and ensuring the safety of the patient, ${ }^{[21]}$ maintain a stable level of consciousness, attain maximum physical functioning and self-care abilities, maximize communication abilities, maintain adequate nutrition and maintain effective personal and family coping. ${ }^{[22]}$ For the two types of stroke either ischemic or hemorrhagic, providing of secondary prevention, with treatment help to control complications that are accompanied with neurological disability, another necessary priority during hospitalization of the stroke patients is evaluation of appropriate type and level of rehabilitation. ${ }^{[23]}$

Effective implementation of management strategies for stroke patients requires improving in therapeutic role of the nurse for helping patients to understand the meaning of the disease, provide emotional support, maintaining normal functions, meeting an essential patient' needs and helping patients to meet rehabilitation goals. ${ }^{[24]}$ Planning for rehabilitation should also begin after stroke as soon as possible. The rehabilitation process becomes more active as the patient becomes medically stable usually within two days. ${ }^{[25]}$ Nurses who manage stroke patients require specfic and contiuous training program to be able to deliver quality of patient-focused care because they are essential members of the stroke neuorological team, thus, educational training program is vital to improve skills that are important for successful management. ${ }^{[26,27]}$ Accordingly, the aim of this study was to evaluate the effect of implementing designed educational training program for neurological nurses on clinical outcomes of stroke patients.

\subsection{Significance of the study}

Increasing numbers of stroke patients leads to the increase in the number of survivors who are living with disabilities which increased the need for qualified nursing care. Previous studies have highlighted the need for research aiming at developing interventions in the neuro-nursing area because there were strong links between updated nursing care and patients' outcomes in the areas of stroke care that improve nurses significant role in controling disability among patients. On the other hand, the researchers found that the nurses who are caring for stroke patients at Neurological Department at Tanta University Hospital had many years of experience regarding care of stroke patients but at the same time there were lack of updated knowledge and practice through newly well-developed training program that must contain accuracy of knowledge about technological advancement that are used during assessment and management of stroke patients, where there was not any training workshop sessions are made in the last several years for these nurses from graduation until now. So, it is vital to create designed educational training programs for nursing staff to keep abreast of updated knowledge 
and practices. ${ }^{[28,29]}$

\subsection{Aim of the study}

Evaluate the effect of implementing designed educational training program for neurological nurses on clinical outcomes of stroke patients.

\section{Research hypothesis}

- Knowledge score about care of stroke patients of neurological nurses is expected to be improved post implementation of designed educational training program.

- Practice scores about care of stroke patients of neurological nurses is expected to be improved post implementation of designed educational training program.

- Stroke Patients will exhibit improvement in their clinical outcomes (activities of daily living and self-care) post application of designed educational training program through nurses.

\section{SUBJECTS AND METHODS}

\subsection{Research design}

A quasi-experimental research design was utilized to conduct the study.

\subsection{Setting}

The study was carried out at Neurological Intensive Care Units, Wards and Neurological outpatient clinics of Tanta Main University Hospital.

\subsection{Subjects}

All nurses $(\mathrm{n}=35)$ from the above mentioned settings who are providing direct care and rehabilitation for patients with stroke.

A purposive sample of 30 patients (male and female) with diagnosis of stroke from the above previously mentioned setting. The sample size was estimated using Epi Info 7 statistical program based on patients admission in the hospital at $95 \%$ confidence power of the study and accepted error $5 \%$.

\subsection{Inclusion criteria for the patients Research hypothesis}

- First admission with diagnosis of stroke.

- Patients' age ranged from 35-60 years old.

- Hospitalized patient post 24 hours from stroke onset.

- Normal level of consciousness.

- Length of stay not less than 2 months.

- Patients who are scheduled for follow up rehabilitation program according to physician report.

\subsection{Exclusion criteria for the patients} Research hypothesis

- Patients with severe cognitive impairment as delirium according to physician report.

- Patients with immediate brain surgery.

- Premorbid activities of daily living (ADL).

- Diagnosed with depression, or an antidepressive treatments.

\subsection{Tools of data collections}

Three tools were used for data collection. These tools were aimed to evaluate the effect of implementing designed educational training program for neurological nurses on clinical outcomes of stroke patients.

\section{Tool (I): Assessment of Nurses' Knowledge Question- naire Sheet}

It was comprised of two parts:

Part (A): Socio-demographic characteristics of nurses included: nurses' code, age, gender, level of education, years of experiences, job description and previous workshop training about care of stroke patients.

Part (B): Nurses' knowledge regarding care of stroke patients. It was developed by the researchers based on related literatures ${ }^{[3,17,30-32]}$ to evaluate nurses' knowledge by selfassessment pre, immediate and 2-months later post implementation of designed educational training program regarding care of stroke patients. It included the following:

- Knowledge about stroke (13) questions which included; definition, risk factors, causes, types, manifestation, warning signs and complication about stroke.

- Knowledge about assessment of stroke patients (16) questions which included; emergency assessment, neurological assessment techniques, assess voluntary and involuntary movements, swallowing assessment, communication assessment.

- Knowledge about care, rehabilitation and secondary prevention of stroke patients (25) questions which included; safety measures, position technique of patients, managing airway and swallowing problems, medications, mobilization, care of skin, rehabilitation technique, exercise program, healthy diet and precautions.

Scoring system of knowledge:

- “Correct answer" scored (1)

- "Don’t know" or "incorrect answer" scored (0)

The total scoring systems of nurses' knowledge were 54 and classified as the following:

- Good: $>60 \%$ of the total score 
- Fair: $\geq 50 \%-60 \%$ of the total score

- Poor: $<50 \%$ of the total score

Tool (II): Observation checklist for nurse's practice regarding care of stroke patients

This tool was developed by the researchers based on relevant literatures ${ }^{[3,17,30-32]}$ to evaluate nursing practice by the researchers; pre, immediate and 2 months later post implementation of designed educational training program regarding care of stroke patients, it included the following steps:

- Assessment (observation management) of stroke patients (12) steps which included practice of: neurological assessment techniques, assess vital signs, assesses pupil size, shape, equality, light reactivity, assess swallowing ability, communication, reflex and muscles strength, hydration status, infection and skin breakdown.

- Care of stroke patients (13) steps which included practice of: manage airway obstruction, positioning techniques, oral hygiene, care of urinary catheterization, prevent contractures, implement good eating and swallowing techniques, skin care.

- Rehabilitation with exercise and secondary prevention (15) steps which included practice of: use assistive ambulatory devices, promote adequate nutrition, instruction about diet, exercise program, assess painful shoulder, spasticity/contractures, maintain balance in a sitting then standing position, provide emotional support for patients.

Scoring system for practice:

- "Done practices" take (1)

- "Not done practices" take (0)

The total scoring systems of nurses' practices score were 40 and classified as:

- Satisfactory: $\geq 60 \%$ of the total score

- Unsatisfactory: $<60 \%$ of the total score

Tool (III): Patient's Clinical Outcomes Assessment Sheet

It included three parts:

Part (A): Socio-demographic characteristics of patients. It included patients' code, age, gender, place of residency, marital status, level of education, work status and smoking habits.

Part (B): Patients' clinical data. It was developed by researchers based on literature reviews ${ }^{[17,32]}$ which used to assess medical data of the patients regarding; types of stroke, history of hypertension and diabetes mellitus, movement 124 disorder, numbness or tingling, asymmetrical face, seizure activity, asymmetric arm weakness, asymmetric leg weakness, bowel field deficit, speech disturbance.

Part (C): Barthel Index of Activities of Daily Living. It was developed by Loewn, ${ }^{[33]}$ Hobart, ${ }^{[34]}$ Jalali R, ${ }^{[35]}$ and Schepers. ${ }^{[36]}$ It was used to evaluate stroke patient's disability and degree of physical or verbal independence immediately and 2 months later after application of the designed nursing educational training program by the researcher to determine patients' physical improvement. Barthel Index of Activities of Daily Living is a 10-item scale of independence, used to evaluate activities that are grouped according to the following: self-care (feeding, grooming, bathing, dressing, bowel and bladder care, and toilet use) and mobility (ambulation, transfers, and stair climbing). Scoring system: Summing the patient's scores for each item.

Total scores from 0 (complete dependence) to 20 (complete independence), with lower scores indicating increased disability, classified as the following:

- Independent: $>60 \%$ from total score

- Need help: 50\%-60\% from total score

- Unable: $<50 \%$ from total score

\subsection{Ethical consideration}

An official permission was obtained from the Head of the Neourological Department at Tanta Main University Hospital. Informed consent was taken from every nurse and every patient after clarifying the procedures and the purpose to participate in the study. They were informed about confidentiality of data collection, their right to refuse participation and to withdraw at any time without any consequences. A code number was used instead of name.

\section{Methods OF DATA COLlECTION}

(1) All tools of the study were developed by the researchers after reviewing relevant literature and used to collect data except Tool (III) part C: Barthel Index of Activities of Daily Living was developed by Loewn. ${ }^{[33]}$

(2) All tools were reviewed for content validity by a panel of 5 expertises in the field of Medical Surgical Nursing and Neurological physicians, Their opinions were elicited regarding tools format and consistency, it was calculated and found to be $98 \%$. The reliability for the study tools was calculated by Cronbach's alpha test; it was 0.897 for Tool (I) part B and 0.980 for Tool (II) and 0.910 for Tool (III) part C.

(3) A pilot study was performed to test the practicality and applicability of the tools and to determine any obstacles that may be encountered during the period of data collection. It 
was conducted on (10\%) from nurses and patients accordingly, needed modification was done. Pilot study from nurses and patients was excluded from the study sample.

(4) This study was conducted at the beginning of September 2017 to the end of February 2018.

(5) Educational training program was carried out through four phases as following: (assessment, planning, implementation and evaluation):

Assessment phase:

Nurses were assessed before beginning of designed educational training program by using Tool (I) part A to collect baseline data and Tool I part B and Tool II were used to evaluate nurses' knowledge and practice related to management of stroke patients pre implementation of educational training program and to determine the needs of the nurses. The knowledge questionnaire sheet was filled by the nurse within 30 minutes and observational check list was filled by the researchers within 50 minutes for each nurse.

Planning phase:

Educational training program was prepared by the researchers according to literature review, ${ }^{[37-43]}$ objectives of the study were determined based on the needs of the study subjects. An illustrative structured booklet was prepared in a simple Arabic language supported by illustrative pictures as a guide for the nurses, and different methods of teaching were used such as video, group discussion and presentation for theoretical part and demonstration \& re-demonstration for the practical part. A booklet was given to each nurse during sessions to refresh their knowledge and skills. Determine the suitable time for data collection through exploratory visit to the settings. The designed educational training program was conducted in 4 sessions (two sessions for theoretical knowledge and two sessions for practical demonstration) to all nurses who are divided to 7 groups; each group was contained 5 nurses, three days/week, the time of each session was about two hours.

Implementation phase:

Assessments of the nurses were done in the first week. Then, they were divided into groups and implementation of the educational training program was carried out at the study settings. Educational training program was implemented by the researchers which were divided into four educational training sessions as the following: The First session was given to the nurses regarding risk factors, manifestation and complication of stroke. The second session was given to the nurses regarding knowledge about management and treatment of stroke that are divided into assessment, care of patients, rehabilita-

Published by Sciedu Press tion and secondary prevention. The third session included demonstration and re-demonstration regarding care of stroke patients which include; assessment and care of patients. The fourth session included demonstration and re-demonstration regarding rehabilitation with exercise and secondary prevention for patients after discharge from hospital. Finally, Assessment sheet of the patients was filled out by the researchers immediately before applied designed educational training program to evaluate baseline, clinical data for stroke patients and level of Barthal index of activities of daily living, then the nurses started to carried out the training program on the studied patients for about 2 months later. Training program for patient was carried out in the morning shift, for about from 1 to 2 hours a day, 2 days a week.

Evaluation phase:

For nurses: Immediately post educational training program and after two month later, the researchers were reassessed knowledge and practice of the nurses to test if there were any improvement in knowledge and practice over time among the participants by using Tool (I) part B and Tool II.

For Patients: Tool III part (A and B) were used to collect baseline and clinical data for patients, and part (C) was carried out to evaluate prognosis and clinical outcomes of patients. Each patient was observed by the researchers (immediately and 2 months later after application of the designed nursing educational training program by the researcher to determine patients' physical improvement). Direct testing of the patient is not needed; information can be derived from relatives and nurses.

\section{Methods of data analysis}

All data were collected, coded, tabulated and subjected to statistical analysis. Statistical analysis is performed by statistical Package SPSS in general (version 20), also Microsoft office Excel is used for data handling and graphical presentation variables. Data expressed as number and percentage. $F$-test is used to determine significant for numeric variable. A probability level of $p$-value $\leq .01$ was adopted as a level of significance for testing the research hypotheses.

\section{Results}

Table 1 showed the distribution of nurses relevant to their socio-demographic characteristics. For about age, the table revealed that high percentage of nurses $(42.9 \%$ and $4 \%$ ) were in the age group (20-25) and (>25-40) years old respectively with mean age $29.66 \pm 7.92$ and more than three quarter of them $(80 \%)$ were female. Regarding the level of education, the table revealed that more than half of nurses $(54.3 \%)$ were Baccalaureate degree and about (45.7\% and $37.1 \%)$ 
from them had (1-5) and ( $\geq 5-10)$ years of experiences respectively. Also more than half of the nurses $(54.3 \%)$ were nursing specialist as job description and majority of them $(88.8 \%)$ have no previous training sessions about care of stroke patients.

Table 1. Distribution of the nurses relevant to their socio-demographic characteristics

\begin{tabular}{lll}
\hline \multirow{2}{*}{$\begin{array}{l}\text { Socio-demographic } \\
\text { characteristics }\end{array}$} & \multicolumn{2}{c}{ Nurses sample $(\mathbf{n}=\mathbf{3 5})$} \\
\cline { 2 - 3 } & No & $\%$ \\
\hline Age (year) & 15 & 42.9 \\
$\bullet 20-25$ & 14 & 40.0 \\
$\bullet>25-40$ & 6 & 17.1 \\
$\bullet>40$ & $29.66 \pm 7.92$ \\
Mean $\pm S D$ & & \\
Gender & & 20.0 \\
$\bullet$ Male & 7 & 80.0 \\
$\bullet$ & 28 &
\end{tabular}

Education level

- Baccalaureate degree 19 54.3

- Diplome 13

- Master's degree

3

8.6

Years of experiences
- 1-5 years
13
37.1
- $\geq 5$-10 years
16
45.7
$\bullet \geq 10-15$ years
6
17.1
Mean $\pm S D$
$6.29 \pm 3.43$

\section{Job description}

- Nurse

- Nursing specialist

6

- Supervisor

Previous training sessions about stroke

- Yes: (1 day) 4

- No 31 88.8

Table 2 showed the levels of nurses' knowledge about risk factors, manifestation and complications of stroke throughout all intervention periods of the study. The table revealed that there were statistically significant improvements in nurses' knowledge about risk factors, manifestation and complications of stroke. Where the majority of the studied nurses (60\%) had poor level of knowledge pre implementation of designed educational training program, whereas they scored good level of knowledge immediately and 2 months later post implementation of educational program for about $(85.7 \%$ and $77.1 \%$ ) respectively with $p$-value $\leq .01$.

Table 3 showed the levels of nurses' knowledge regarding assessment of stroke patients throughout all intervention periods of the study. The table revealed that there were significant improvements in nurses' knowledge about assessment for stroke patients. Where the majority of the nurses $(74.3 \%)$ had poor level of knowledge pre implementation of designed educational training program, whereas they scored good level of knowledge immediately and 2 months later post implementation of educational program for about $(82.9 \%$ and $62.9 \%)$ respectively with $p \leq .01$.

Figure 1 showed the levels of nurses' knowledge regarding care, rehabilitation and secondary prevention of stroke patients throughout all intervention periods of the study. The figure revealed that there were statistically significant improvements in nurses' knowledge about care, rehabilitation and secondary prevention of stroke patients. Where the majority of the studied nurses (80\%) had poor level of knowledge pre implementation of designed educational training program, whereas they scored good level of knowledge immediately and 2 months later post implementation of educational program for about ( $88.4 \%$ and $82.9 \%)$ respectively.

Figure 2 showed the levels of nurses' practice regarding assessment of stroke patients throughout all intervention periods of the study. The figure showed that there were statistically significant improvements among nurses' practice regarding assessment of stroke patients. Where the majority of the studied nurses $(80 \%)$ had unsatisfactory level of practice pre implementation of designed educational training program, whereas they scored satisfactory level of practice immediately and 2 months later post educational program for about $(87 \%$ and $75 \%)$ respectively.

Table 4 showed the levels of nurses' practice about care for stroke patients throughout all intervention periods of the study. The table showed that there were significant improvements among nurses' practice regarding care for stroke patients. Where the majority of the nurses $(82.9 \%)$ had unsatisfactory level of practice pre implementation of educational training program, whereas they scored satisfactory level of practice immediately and 2 months later post implementation of educational training program for about ( $82.9 \%$ and $77.1 \%$ ) respectively with $p$-value $\leq .01$. 
Table 2. Levels of nurses' knowledge about risk factors, manifestation and complication of stroke throughout all intervention periods of the study

\begin{tabular}{|c|c|c|c|c|c|c|}
\hline \multirow{3}{*}{$\begin{array}{l}\text { Levels of nurses } \\
\text { knowledge }\end{array}$} & \multicolumn{6}{|c|}{ Intervention periods $(\mathrm{n}=\mathbf{3 5})$} \\
\hline & \multicolumn{2}{|c|}{ Pre-educational program } & \multicolumn{2}{|c|}{$\begin{array}{c}\text { Immediately post } \\
\text { educational program }\end{array}$} & \multicolumn{2}{|c|}{$\begin{array}{c}2 \text { months post educational } \\
\text { program }\end{array}$} \\
\hline & No & $\%$ & No & $\%$ & No & $\%$ \\
\hline Poor $<(50 \%)$ & 21 & 60 & 1 & 2.9 & 3 & 8.6 \\
\hline Fair $\geq(50 \%-60 \%)$ & 13 & 37.1 & 4 & 11.4 & 5 & 14.3 \\
\hline Good $>(60 \%)$ & 1 & 2.9 & 30 & 85.7 & 27 & 77.1 \\
\hline$F$ & 48.40 & & & & & \\
\hline$p$ & $.000^{*}$ & & & & & \\
\hline
\end{tabular}

Table 3. Levels of nurses' knowledge about assessment for stroke patients throughout all intervention periods of the study

\begin{tabular}{|c|c|c|c|c|c|c|}
\hline \multirow{3}{*}{$\begin{array}{l}\text { Levels of nurses } \\
\text { knowledge }\end{array}$} & \multicolumn{6}{|c|}{ Intervention periods $(n=35)$} \\
\hline & \multicolumn{2}{|c|}{ Pre-educational program } & \multicolumn{2}{|c|}{$\begin{array}{c}\text { Immediately post } \\
\text { educational program }\end{array}$} & \multicolumn{2}{|c|}{$\begin{array}{c}2 \text { months post educational } \\
\text { program }\end{array}$} \\
\hline & No & $\%$ & No & $\%$ & No & $\%$ \\
\hline Poor $<(50 \%)$ & 26 & 74.3 & 1 & 2.9 & 3 & 8.6 \\
\hline Fair $\geq(50 \%-60 \%)$ & 7 & 20.0 & 5 & 14.3 & 10 & 28.5 \\
\hline Good $>(60 \%)$ & 2 & 5.7 & 29 & 82.9 & 22 & 62.9 \\
\hline$F$ & 116.92 & & & & & \\
\hline$p$ & $.000^{*}$ & & & & & \\
\hline
\end{tabular}

nurses' knowledge about care, rehabilitation and secondary prevention of stroke patients

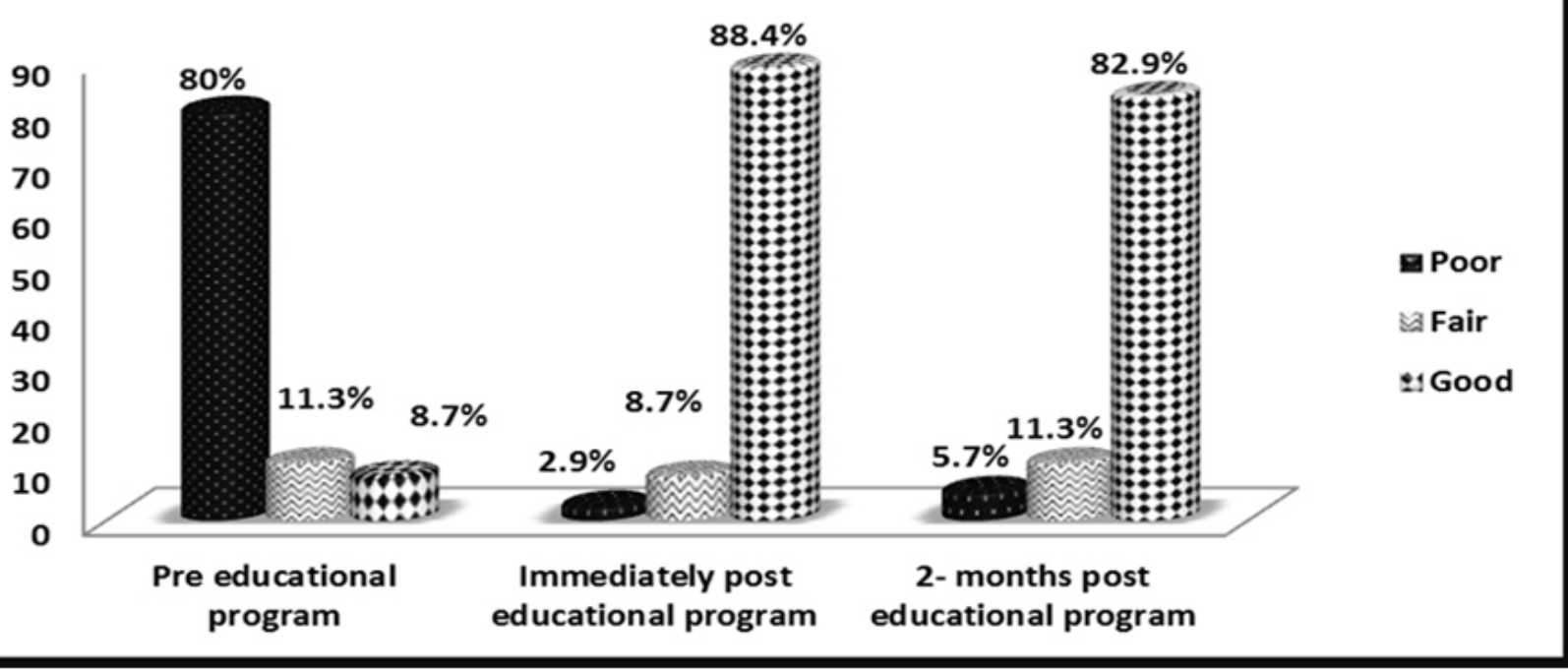

Figure 1. Levels of nurses' knowledge regarding care, rehabilitation and secondary prevention of stroke patients through all intervention periods of the study 


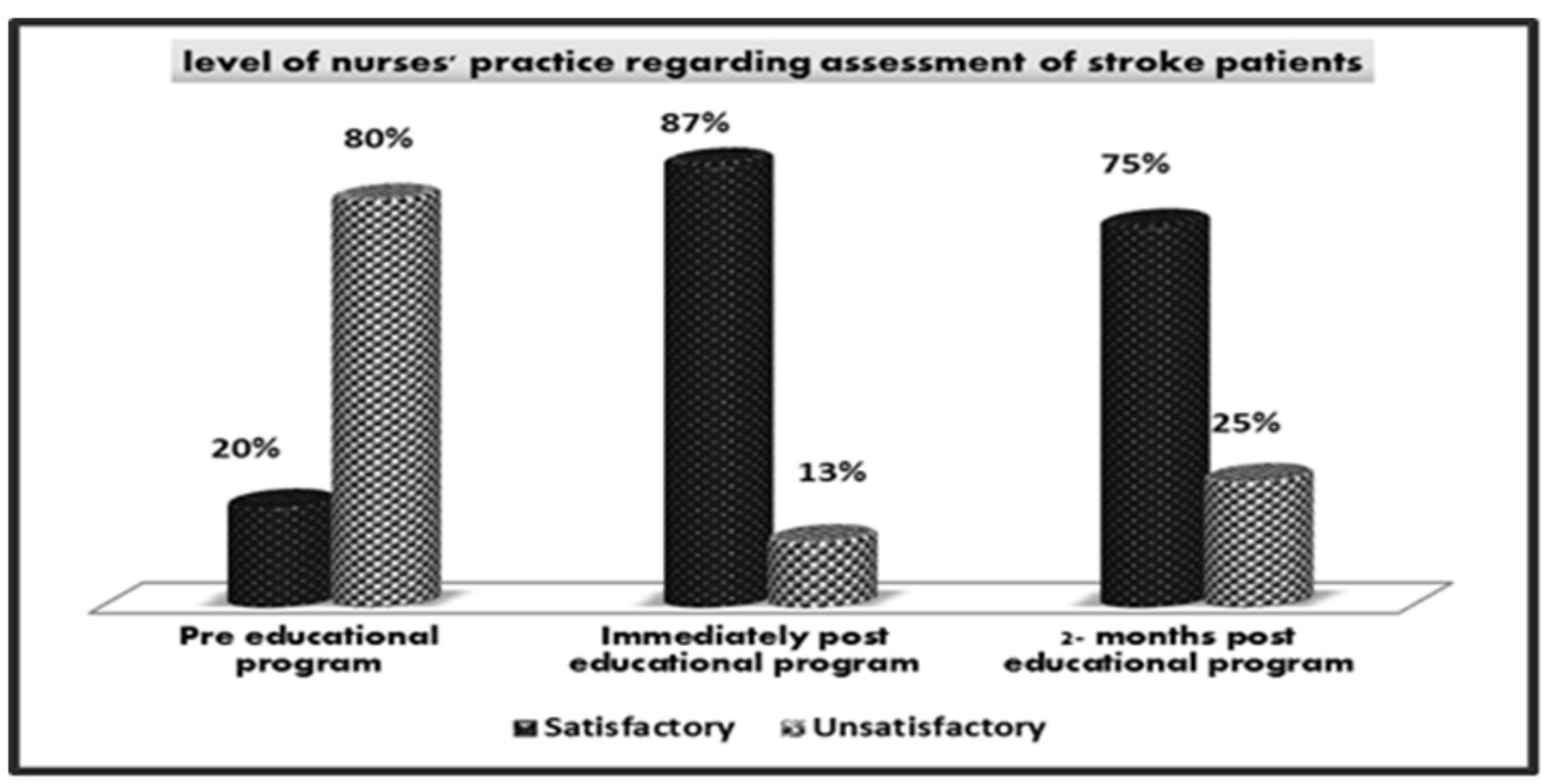

Figure 2. Levels of nurses' practice regarding assessment of stroke patients throughout all intervention periods of the study

Table 4. Levels of nurses' practice regarding care for stroke patients throughout all intervention periods of the study

\begin{tabular}{|c|c|c|c|c|c|c|}
\hline \multirow{3}{*}{$\begin{array}{l}\text { Levels of care for stroke } \\
\text { patients }\end{array}$} & \multicolumn{6}{|c|}{ Intervention periods $(\mathrm{n}=\mathbf{3 5})$} \\
\hline & \multicolumn{2}{|c|}{ Pre-educational program } & \multicolumn{2}{|c|}{$\begin{array}{c}\text { Immediately post } \\
\text { educational program }\end{array}$} & \multicolumn{2}{|c|}{$\begin{array}{c}2 \text { months post educational } \\
\text { program }\end{array}$} \\
\hline & No & $\%$ & No & $\%$ & No & $\%$ \\
\hline Unsatisfactory $\geq 60 \%$ & 29 & 82.9 & 6 & 17.1 & 8 & 22.9 \\
\hline Satisfactory $<60 \%$ & 6 & 17.1 & 29 & 82.9 & 27 & 77.1 \\
\hline$F$ & 25.88 & & & & & \\
\hline$p$ & $.000^{*}$ & & & & & \\
\hline
\end{tabular}

Figure 3 showed the levels of nurses' practice regarding rehabilitation and secondary prevention of stroke patients throughout all intervention periods of the study. The figure showed that there were statistically significant improvements among nurses' practice regarding rehabilitation and secondary prevention of stroke patients. Where the majority of the nurses $(79 \%)$ had unsatisfactory level of practice pre implementation of designed educational training program, whereas they scored satisfactory level of practice immediately and 2 months later post implementation of educational training program for about $(84 \%, 81 \%)$ respectively.

Table 5 showed the distribution of stroke patients' relevant to their socio-demographic characteristics. As regards age, the table revealed that nearly three quarter of patients (70\%) were in the age group $(<55-60)$ with mean $55.45 \pm 10.29$ and more than half of them (53.3\%) were female. Regarding marital status, the table revealed that more than half of patients $(53.3 \%)$ were married. As for educational level, the table showed that $(50.0 \%$ and $20.0 \%)$ from patients were iliterate and university educated respectively. Majority of patients (46.7\% and 36.3\%) were from rural and city area respectively. Also the majority of them (50.0\% and 43.3\%) were house wives and employers respectively and (63.3\%) were not smokers. 


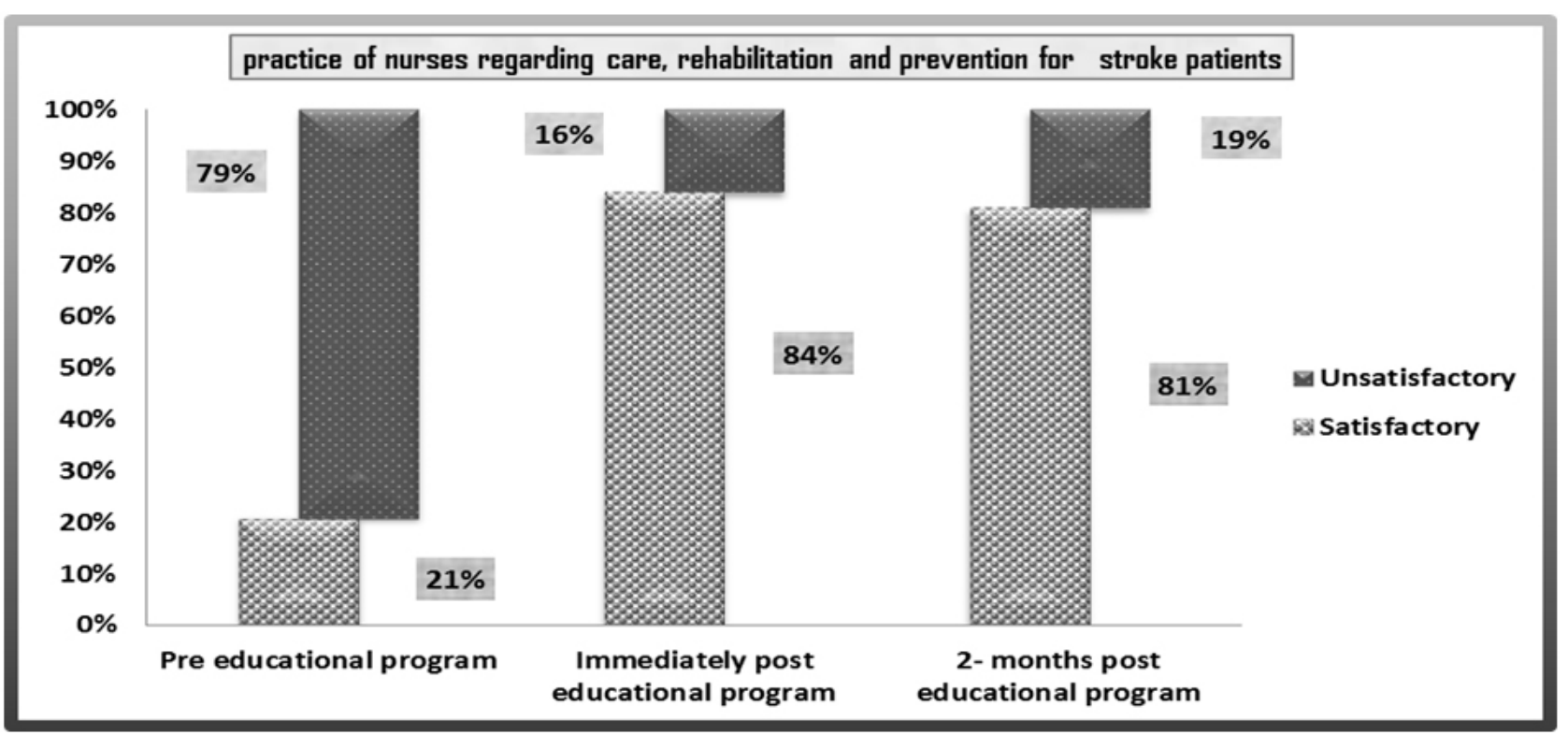

Figure 3. Levels of nurses' practice regarding rehabilitation and secondary prevention of stroke patients throughout all intervention periods of the study

Table 5. Distribution of stroke patients' relevant to their socio-demographic characteristics

\begin{tabular}{|c|c|c|}
\hline \multirow{2}{*}{$\begin{array}{l}\text { Socio-demographic } \\
\text { characteristics }\end{array}$} & \multicolumn{2}{|c|}{ Patients' sample $(n=30)$} \\
\hline & No & $\%$ \\
\hline \multicolumn{3}{|l|}{ Age (year) } \\
\hline$\bullet \geq 35-55$ & 9 & 30.0 \\
\hline - $<55-60$ & 21 & 70.0 \\
\hline \multicolumn{3}{|l|}{ Gender } \\
\hline - Male & 14 & 46.7 \\
\hline - Female & 16 & 53.3 \\
\hline \multicolumn{3}{|l|}{ Marital status } \\
\hline - Single & 6 & 20.0 \\
\hline - Married & 16 & 53.3 \\
\hline - Widow & 6 & 20.0 \\
\hline - Divorced & 2 & 6.7 \\
\hline \multicolumn{3}{|l|}{ Education level } \\
\hline - literacy & 15 & 50.0 \\
\hline - Secondary level & 5 & 16.7 \\
\hline - Diplome & 4 & 13.3 \\
\hline - University & 6 & 20.0 \\
\hline \multicolumn{3}{|l|}{ Place of residency } \\
\hline - Rural & 14 & 46.7 \\
\hline - Urban & 5 & 16.7 \\
\hline - City & 11 & 36.3 \\
\hline \multicolumn{3}{|l|}{ Work status } \\
\hline - House wife & 15 & 50.0 \\
\hline - Employer & 13 & 43.3 \\
\hline - Not work & 2 & 6.7 \\
\hline \multicolumn{3}{|l|}{ Smoking habits } \\
\hline - Yes & 11 & 36.7 \\
\hline - $\mathrm{No}$ & 19 & 63.3 \\
\hline
\end{tabular}

Table 6. Distribution of the studied stroke patients relevant to their clinical data

\begin{tabular}{lll}
\hline \multirow{2}{*}{ Clinical data for stroke patients } & \multicolumn{2}{c}{ Studied sample $(\mathbf{n}=\mathbf{3 0})$} \\
\cline { 2 - 3 } & $\mathbf{N}$ & $\%$ \\
\hline Type of stroke & & \\
- Ischemic stroke & 26 & 86.7 \\
- Hemorrhagic stroke & 4 & 13.3
\end{tabular}

History of hypertension
- Yes
17
56.7
- No
13
43.3

History of Diabetes
- Yes

- No

Movement disorder

Numbness or tingling

Asymmetrical face

Seizure activity

Asymmetrical arm weakness

Asymmetrical leg weakness

Bowel field disorder

Speech disturbance
19

11

24

26

15

9

23

21

15

22
63.3

36.7

80

86.7

50

30

76.7

70

50

73.3 
Table 6 showed the distribution of stroke patients relevent to their clinical data. The table showed that the majority of patients $(80 \%)$ were diagnosed as ischemic stroke and the majority of them $(56.7 \%$ and $63.3 \%)$ had history of hypertension and diabetes respectively. In addition to majority of them $(80 \%, 86.7 \%, 50 \%, 76.7 \%, 70 \%, 50 \%$ and $73.3 \%)$ suffered from: movement disorders, numbness and tingling, symmetrical face, asymmetrical arm weakness, asymmetrical leg weakness, bowel field deficits and speech disorders respectively.

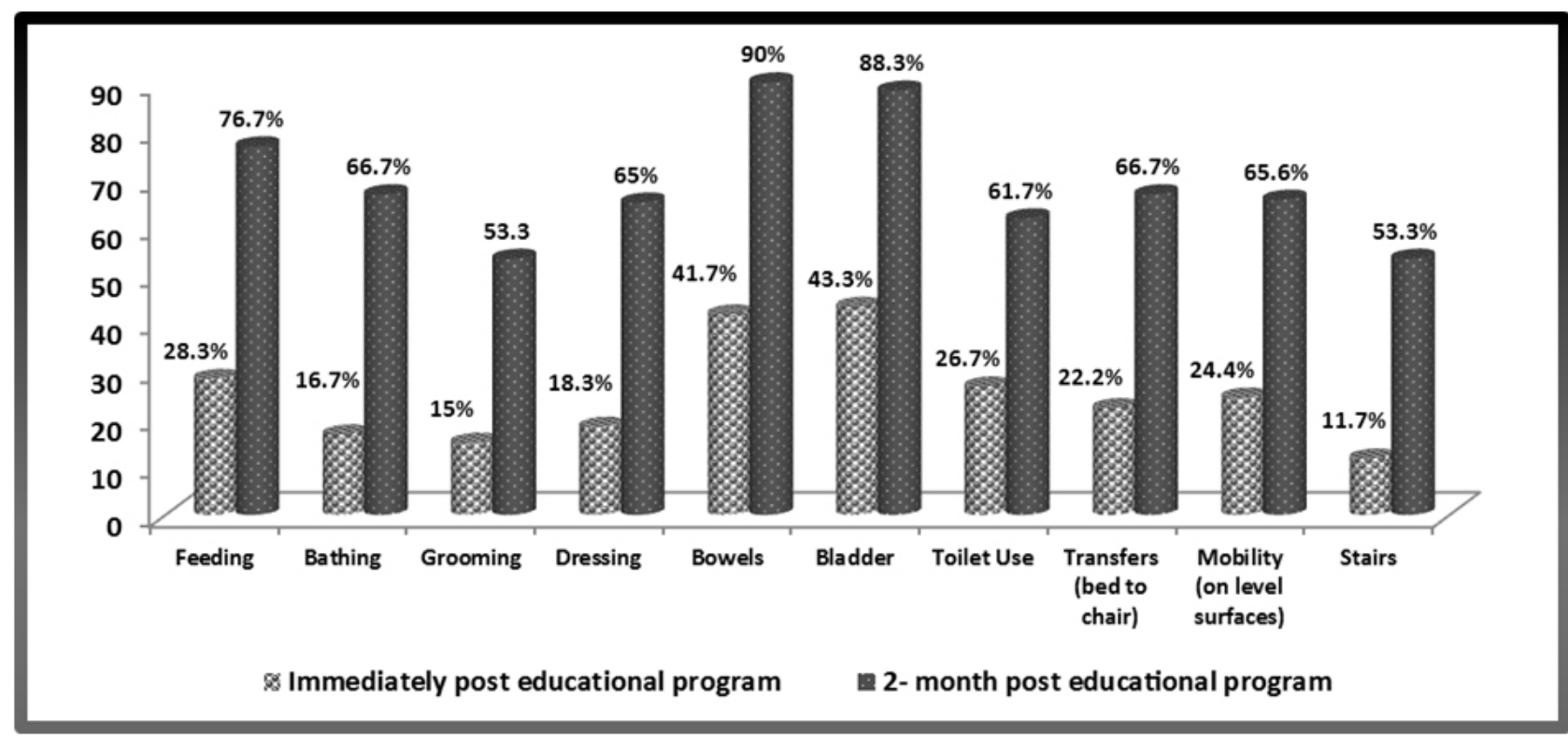

Figure 4. Levels of Barthel index of activities of daily living items for stroke patients from immediately to 2 months post implementation of educational program

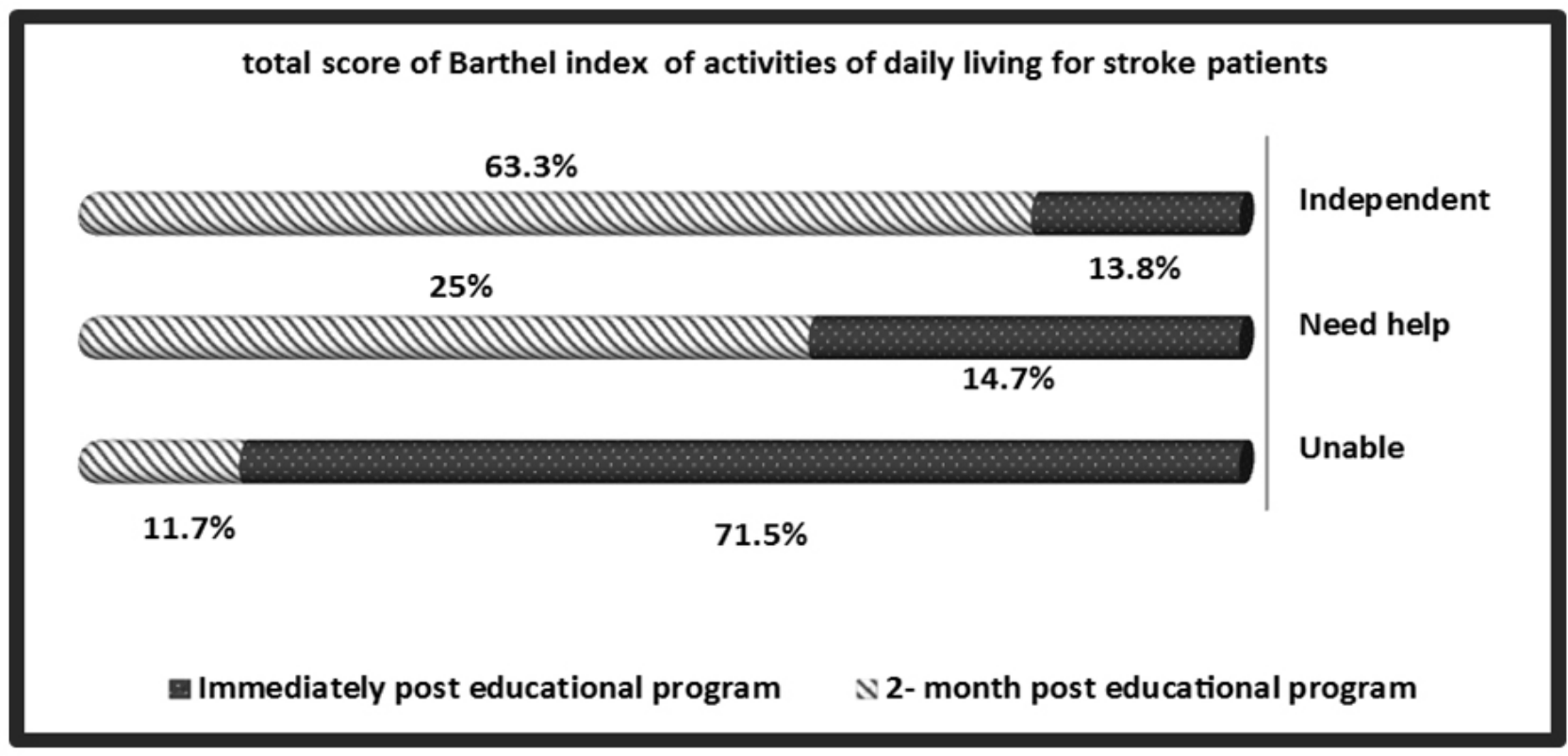

Figure 5. Total score of Barthel index of activities of daily living for stroke patients from immediately to 2 months post implementation of educational program 
Figure 4 showed the levels of Barthal index of activities of daily living items for stroke patients from immediately to 2 months post educational program. The figure showed that there were significant improvements in levels of Barthal index of activities of daily living for stroke patients regarding; (feeding, bathing, grooming, dressing, bowels, bladder, toilet use, transfers, mobility and stairs) as following: from immediately $(28.3 \%, 16.7 \%, 15 \%, 18.3 \%, 41.7 \%, 43.3 \%$, $26.7 \%, 22.2 \%, 24.4 \%$ and $11.7 \%)$ respectively to $(76.7 \%$, $66.7 \%, 53.3 \%, 65 \%, 90 \%, 88.3 \%, 61.7 \%, 66.7 \%, 65.6 \%$ and $53.3 \%$ ) respectively post 2 months later from implementation of designed educational training program.

Figure 5 showed the total score of Barthel index of activities of daily living for stroke patients from immediately to 2 months post educational program. The figure showed that there were improvements in stroke patients' activities of daily living. Whereas the majority of the studied patients (71.5\%) were unable to perform activities of daily living immediately post educational program, (25\% and $63.3 \%)$ from them needed help and were independent in performance of activities of daily living and self-care respectively post 2 months from educational program.

\section{Discussion}

A stroke is a serious life-threatening medical condition that occurs when blood supply to the part of the brain is cut off. Prompt management is crucial to minimize potential complications. ${ }^{[4]}$ Improving knowledge about management of stroke through educational program for nurses can promote secondary prevention. ${ }^{[45]}$ This study aimed to evaluate the effect of implementing designed educational training program for neurological nurses on clinical outcomes of stroke patients. Concerning socio-demographic data of the nurses, the study results showed that the majority of nurses were in the age group (20-25) and (> 25-40) years/old and more than three quarter of them were female. Regarding the level of education, more than half of nurses were Baccalaureate degree and nearly half of them had 1-5 years of experience. Also the majority of them were nursing specialists with no previous training about care of stroke patients.

These results were congruent with Traynelis ${ }^{[46]}$ who reported that in his study about nurses' knowledge regarding ischemic stroke, the study sample consisted of 53\% registered nurses from various educational levels. In addition to Lawrence et al., ${ }^{[47]}$ who revealed that in their study about a survey of stroke nurses' knowledge that the majority of the nurses aged from 40 to 50 years and $(89.7 \%)$ from them were female, reflecting the gender distribution of the nursing profession, also the majority of them had 6-10 years of experience. More-

Published by Sciedu Press over, Johnson et al. ${ }^{[48]}$ found that in their study the age of the neurological nurses ranged from 24 to 47 years old. Also years of experience were 45 months and the majority of them didn't receive training course about early mobilization of stroke patients.

Regarding levels of nurses' knowledge about stroke, the study results revealed that there were highly statistically significant improvements among nurses' knowledge throughout all intervention periods of the study from pre, immediate and 2 months from program regarding risk factors, manifestation, complication, assessment, rehabilitation and secondary prevention. This improvement of nurses' knowledge post implementation of designed educational program may be due to the fact that there was lack of previous in-service training programs among nurses and absence of updated knowledge through workshop sessions which improved the quality of nursing care. Moreover, the nurses lacked the efficiency of updating their knowledge after being settled in the clinical environment for a longer time.

These findings were in accordance with Schneider ${ }^{[49]}$ who reported that improving awareness among nurses about causes and warning signs of stroke is essential for preventive purposes and for immediate medical treatment. In addition, Jouria and Katz ${ }^{[50]}$ revealed that nurses who care for stroke patients should attend training program and specialized lectures, also they should participate in continuing educational training that are focused on cerebrovascular disease such as stroke. Moreover, Kabita and Ajish ${ }^{[18]}$ mentioned that patient and family education is one of the important concepts of the nursing role during care for the stroke patient, so nurses should give specific attention to three areas: selfmanagement, disease prevention and disease-specific education.

Furthermore, Reynolds et al. ${ }^{[51]}$ reported that significant improvement in nursing knowledge was noted among nurses of the neurological problems and other assessment subscale score as well as the total stroke knowledge assessment score post guidelines. In addition to Duffy et al. ${ }^{[52]}$ who mentioned that after receiving educational program about stroke, nurses gained knowledge about assessments and importance of follow-up program for patients. Moreover, Han and Chen ${ }^{[53]}$ mentioned that the majority of nurses recognize hypertension as a risk factor for stroke, whereas awareness about other common risk factors as unhealthy lifestyle including smoking and lack of exercise as a risk factor for stroke was low. In addition, Baker ${ }^{[54]}$ found that nurses who are managing stroke patients require specific educational and training program to be able to deliver patient-focused care and prevent secondary complications. 
Regarding nurses' practice about management of stroke patients, the study results revealed that there were highly statistically significant improvements among nurses' practice about management of stroke patients throughout all intervention periods of the study from pre, immediate to 2 months post program regarding; assessment, care, rehabilitation and secondary prevention of stroke patients. This improvement of nurses' practice post implementation of designed educational program may be attributed to that inadequate updating clinical training course for neurological nurses regarding management of the stroke patient due to overloaded area of working, lack of funding for organizing regular workshops and the nurses' time shortage but the researchers tried to overcome these challenges.

These results were congruent with Long et al.. ${ }^{[55]}$ who mentioned that in their study the influence of the educational program about stroke is shown in the participants' moves towards adopting a more rehabilitative philosophy in their nursing practice as evidenced by their moves away from the "doing for" style of physical interaction. Moreover, Elsayed $^{[56]}$ reported that, it is necessary to improve nurses' knowledge in neurological intensive care units about initiative diagnosis of stroke to support clinical practice skills toward improved outcomes of patients with cerebrovascular accidents disease, because improving performance in the intensive care unit would decrease morbidity rate and improve quality of care for stroke patient.

In addition, Whitehead and Barton ${ }^{[57]}$ reported that in the U.K. study that there were decrease in nursing clinical practice capabilities due to about $78 \%$ of nursing students' and nursing staff were not aware about stroke management. These results also were congruent with Rowat et al., ${ }^{[58]}$ who found that stroke nurses are ideally placed to assume a significant role regarding practice of secondary prevention, as they work closely with patients who have had a stroke and their families. Also, Islam et al. ${ }^{[59]}$ reported that nursing students have a very low level of practice regarding stroke patient managements which was correlated with their relatively low awareness of stroke warning signs and risk factors. Moreover, Eldesouky ${ }^{[60]}$ reported that the findings of the present study have shown statistically significant improvements in nurses' practice regarding assessment of patients by using GCS after program implementation.

Concerning socio-demographic data of the patients, the study results revealed that the majority of patients were in the age group $(<55-60)$ years/old and more than half of them were female. Regarding marital status the study findings showed that more than half of the patients were married and half of them were iliterate. Nearly half of the patients were from rural area. Also half of the patients were house wives and the majority of them were not smokers. These results were in the same line with Subha et al., ${ }^{[61]}$ who mentioned that the patients within age 56 years old are the dominant age for the study sample from stroke patients. This reveals that stroke is more common among old age people, which can be the beginning of many physiological changes which include narrowing or blockage of blood vessels of the brain.

These results were in contrast with Zhang et al., ${ }^{[62]}$ who mentioned that in their study, that the majority of the study stroke patients were males. Moreover, AL-Abedi and Hamza ${ }^{[63]}$ reported that in a study about self-care for patients' with stroke that over half of the sample (51\%) is illiterates, and $78 \%$ of them are living in urban area and majority of the study sample (84\%) were married. Meanwhile, Ali ${ }^{[64]}$ mentioned that the high percentage from patients under diagnosis of stroke were not smokers. In the present study the reason for decrease number of smoking patients may be due to either denial or majority of women in the study samples.

Regarding clinical data for stroke patients, the study results revealed that the majority of patients were diagnosis as ischemic stroke with history of hypertension and diabetes. In addition to, the majority of patients suffered from; movement disorders, numbness and tingling, symmetrical face, asymmetrical arm weakness, asymmetrical leg weakness, bowel field deficits and speech disorders. These results were in the same line with $\mathrm{Ali}^{[64]}$ and Sheean ${ }^{[65]}$ who mentioned that slightly more than one-third of stroke patients having little such as loss in mobility and speech problems which occur following stroke and more than one quarter of stroke patients had visual problems, so neurological nurse has major roles during care of these patients to improve physical and functional abilities. Also Burneo et al. ${ }^{[66]}$ revealed that majority of stroke patients had seizures activity and movement disorders for about $2.7 \%$ only from patient which improved after management.

Regarding Barthal index for activities of daily living for patients with stroke, the study results revealed that there were improvements in functional ability of the patients regarding feeding, bathing, grooming, dressing, bowels, bladder, toilet use, transfers, mobility and stairs from immediately to post 2 months from implementation of educational program. Moreover, there was improvement in the total score of Barthel index of activities of daily living for stroke patients, where the majority of the patients were independent post 2 months from educational program. This improvement in patients' functional ability may be due to that the nurses were scientifically prepared according to the type of stroke 
patients' disability and nursing activities carried out in a standard manner and depended on evidence-based practice that will contribute to improve patients' outcomes. Also, due to positive impact of the program on the patients due to continuous communication and encouragement of the researchers to patients.

These results were in the same line with Zaky and Moham$\operatorname{mad}^{[67]}$ who mentioned that the result of their study showed increase in stroke patients' activities of daily living that are determined by Barthel index activities of daily living scale post implementation of management (posttest II) than pretest and posttest $I$ in study group than control group. In addition to Kollen et al., ${ }^{[68]}$ who reported that nurses must focus on physical and functional disabilities during care of stroke patients in the first month following stroke, this leads to control of physical disabilities, enhance patient's return to normal life, preserve overall health status, and reduce incidence of disabilities.

In the same line Debbie and Janice ${ }^{[69]}$ mentioned that, stroke patients had a significant increase in the mobility after inpatients care, and this was associated with an increase in daily walking. Also, Lina et al, ${ }^{[70]}$ reported that the rehabilitation program should encompass all physical, social and psychological needs of a stroke survivor's life that increase significant effect on functional ability of the stroke patients. Moreover, Stefan et al. ${ }^{[71]}$ mentioned that, successful rehabilitation for stroke patients depends on systematic management by all neurological staff team specialists which can provide patients with the best functional results.

\section{Conclusions}

Based on the findings of the present study, it can be concluded that:

- There were statistical significant improvements in nurses' knowledge and practice for management of stoke patients immediately and two months later post educational training program than pre intervention period.

- Implementation of educational training program for stroke patient revealed an improvement in patient's clinical outcomes post 2 months from application of educational program.

- There were significant improvements of patients' activities of daily and self care (measured by Barthel index) after implementation of educational training program.

\subsection{Recommendations}

Based on the finding of the present study, the researchers recommended:

- The importance of implementing continuous training and periodic in-service program for neurological nurses regarding management of stroke patient for continuous updating their knowledge and practice.

- Strategies that are provided to stroke patients to decrease complications and disabilities must be included in the routine hospital care.

- Further research for many hospitals on nurses and student nurse is recommended to update information among them, evaluate needed curriculum content, and determine which practice matters are most effective.

\subsection{Limitations of this study}

The limitations of this study were lack of familiarity of many nurses with action research, nurses' resistance due to increased workload, responsibility in the clinical field, and time-consuming nature of the study.

\section{CONFLicts OF INTEREST Disclosure}

The authors declare they have no conflicts of interest.

\section{REFERENCES}

[1] Timby B, Smith N. Introductory Medical Surgical Nursing, 10th ed. Wolters Kluwer Health, Lippincott, Williams \& Wilkins, J. B. Lippincott Company; 2010. 594 p. PMid: 21190418.

[2] World Health Organization. Global Burden of Disease (GBD). Accessed 20 Dec 2017. Available from: www. who. int.access. lib rary.unisa.edu.au/healthinfo/bod/en/index.html

[3] Farraga M, Orabyb M, Ghalic A, et al. Public stroke knowledge, awareness, and response to acute stroke: Multicenter study from 4 Egyptian governorates. Journal of the Neurological Sciences. 2018;
384: 46-49. PMid: 29249376. https://doi.org/10.1016/j.jn s.2017.11.003

[4] Aslani Z, Alimohammadi N, Taleghani F, et al. Nurses' Empowerment in Self-Care Education to Stroke Patients: An Action Research Study. Int. J. Community Based Nurs. Midwifery. 2016; 4(4): 329338.

[5] Summers D, Leonard A, Wentworth D, et al. Comprehensive overview of nursing and interdisciplinary care of to the acute ischemic stroke patient. Stroke. 2009; 40(8): 2911-44. PMid: 19478222 https://doi.org/10.1161/STROKEAHA.109.192362 
[6] Luker J, Bernhardt J, Graham J, et al. Interventions for the uptake of evidence-based recommendations in acute stroke settings, Cochrane Effective Practice and Organisation of Care Group. 2017; 5: 6. https://doi.org/10.1002/14651858.CD012520

[7] Sacco R, Kasner S, Broderick J, et al. An updated definition of stroke for the 21st century: a statement for healthcare professionals from the American Heart Association/American Stroke Association. 2013; 44(7): 2064-89.

[8] Sims N, Muyderman H, Mitochondria A. Oxidative metabolism and cell death in stroke. Biochimica et Biophysica Acta. 2010; 1802(1): 80-91. PMid: 19751827. https://doi.org/10.1016/j.bbadis .2009 .09 .003

[9] Moreau F, Yang R, Nambiar V, et al. Near-infrared measurements of brain oxygenation in stroke. Neurophotonics, 2016; 3(3): $031403-$ 031403. PMid: 26958577. https://doi.org/10.1117/1.NPh. 3.3.031403

[10] Naess H, Lunde L, Brogger J. The triad of pain, fatigue, and depression in ischemic stroke patients: the Bergen Stroke Study. Cerebrovasc Dis. 2012; 33: 461. PMid: 22488041. https ://doi.org/ 10.1159/000336760

[11] Miller E, Murray L, Richards L. American Heart Association Council on Cardiovascular Nursing and the Stroke Council. Comprehensive overview of nursing and interdisciplinary rehabilitation care of the stroke patient: a scientific statement from the American Heart Association. Stroke. 2010; 41(10): 2402-2448. PMid: 20813995. https://doi.org/10.1161/STR.0b013e3181e7512b

[12] Lincoln N, Brinkmann N, Cunningham S. Anxiety and depression after stroke: a 5 year follow-up. Disabil Rehabil. 2013; 35(2): 140-145. PMid: 22725629. https ://doi.org/10.3109/09638288.2012. 691939

[13] Gebruers N, Vanroy C, Truijen S, et al. Monitoring of physical activity after stroke: a systematic review of accelerometry-based measures. Arch. Phys. Med. Rehabil. 2010; 91(2): 288-297. PMid: 20159136. https://doi.org/10.1016/j.apmr.2009.10.025

[14] Jakel A, Plested M, Chapman A. Management of patients with transient ischemic attack: insight from real-life clinical practice in Europe and the United States, Curr. Med. Res. Opin. 2012; 28: 429. PMid: 22185430. https ://doi.org/10.1185/03007995. 2011. 652257

[15] Lai C, Tsai M, Luo J, et al. Post-acute care for stroke - a retrospective cohort study in Taiwan. Patient Preference and Adherence. 2017; 11: 1309-1315. PMid: 28814838. https://doi.org/10.2147/PPA. $\mathrm{S} 136041$

[16] Gocan S, Fisher A. Neurological assessment by nurses using the national institutes of health stroke scale: Implementation of best practice guidelines. Canadian Journal of Neuroscience Nursing. 2008; 30(3): 31-42. PMid: 18856096.

[17] Catangui E. Specialized stroke nursing program using an interprofessional approach: A nurse-driven education initiative of one stroke hospital in Saudi Arabia. Journal of Nursing Education and Practice. 2015; 5(11): 66, 85-87. https ://doi.org/10.5430/jn ep. v5n11p81

[18] Kabita K, Ajish S. Evidence based nursing care for an acute stroke: Theoretical Study. The Degree Programme of Nursing Vaasa, Finland. $2016 ; 5$.

[19] Dupont S, Wijdicks E, Lanzino G. Aneurysmal subarachnoid hemorrhage: an overview for the practicing neurologist. Semin Neurol. 2010; 30: 545. PMid: 21207347. https://doi.org/10.1055/ s-0030-1268862

[20] Mantik L. Medical-surgical nursing: assessment and management of clinical problems. St. Louis, Missouri: Mosby Co; 2014.1388-13399 p. PMid: 24870763.
[21] Alberts M, Latchaw R, Selman W, et al. Recommendations for comprehensive stroke centers: a consensus statement from the brain attack Coalition. Stroke. 2005; 36(7): 1597-1616. PMid: 15961715 https://doi.org/10.1161/01.STR.0000170622.07210.b4

[22] Mazzucco S, Turri G, Mirandola R. What is still missing in acutephase treatment of stroke: a prospective observational study. Neurol Sci. 2013; 34(4): 449. PMid: 22466805. https ://doi.org/10.1 007/s10072-012-1024-y

[23] Alexandrov A, Sharma V, Lao A, et al. Reversed Robin Hood syndrome in acute ischemic stroke patients. Stroke. 2007; 38(11): 3045 3048. PMid: 17916768. https://doi.org/10.1161/STROKEAH A. 107.482810

[24] Booth J, Hillier V, Waters K, et al. Effects of stroke rehabilitation education programme for nurses. Journal of Advanced Nursing. 2005; 49(5): 465-473. PMid: 15713178. https://doi.org/10.1111/j . 1365-2648.2004.03319.x

[25] Lansberg M, Bluhmki E, Thijs V. Efficacy and safety of tissue plasminogen activator 3 to 4.5 hours after acute ischemic stroke: a meta-analysis. Stroke. 2009; 40(7): 2438-41. PMid: 19478213. https://doi.org/10.1161/STROKEAHA.109.552547

[26] Department of Health. National Stroke Strategy. Gateway ref. 9025. DH, London. 2007; 3: 4.

[27] Dennis M, Lewis S, Warlow C. Effect of timing and method of enteral tube feeding for dysphagic stroke patients (FOOD): a multicentre randomised controlled trial. Lancet. 2005; 365(9461): 764-772. https://doi .org/10.1016/S0140-6736(05)70999-5

[28] McCormack J, Reay H. Acute stroke research: Challenges and opportunities for nurses. Nursing Standard. 2013; 27(32): 39-45. https://doi.org/10.7748/ns2013.04.27.32.39.e7142

[29] Green T, Kelloway L, Davies-Schinkel C, et al. Nurses' accountability for stroke quality of care: Part one: Review of the literature on nursing-sensitive patient outcomes. Canadian Journal of Neuroscience Nursing. 2011; 33(3): 13-23. PMid: 22338209.

[30] Cerebrovascular Accident (Stroke). Nursing Care Plans. Matt Vera. 2013. Available from: https://nurseslabs.com/

[31] Catangui E, Slark J. The development and evaluation of interdisciplinary training program for stroke. British Journal of Neuroscience Nursing. 2012; 8(1): 8-11. https://doi.org/10.12968/bjnn. 2012.8.1.8

[32] Andersen H, Eriksen K, Brown A, et al. Follow-up services for stroke survivors after hospital discharge: a randomized control study. Clin. Rehabil. 2002; 16: 593-603. PMid: 12392333. https : //doi.org/10.1191/0269215502cr528oa

[33] Loewen S, Anderson B. Predictors of stroke outcome using objective measurement scales. Stroke. 1990; 21: 78-81. https ://doi .org/ 10.1161/01.STR. 21.1.78

[34] Hobart J, Thompson A. The five item Barthel index. J Neurol Neurosurg Psychiatry. 2001; 71: 225-230. https://doi.org/10.1136/ jnnp.71.2.225

[35] Jalali R, Dutta D, Kamble R. Prospective assessment of activities of daily living using modified Barthel's Index in children and young adults with low-grade gliomas treated with stereotactic conformal radiotherapy. J. Neuro-oncol. 2008; 90: 321-328. PMid: 18704269. https ://doi.org/10.1007/s11060-008-9666-6

[36] Schepers V, Ketelaar M, Visser-Meily J. Responsiveness of functional health status measures frequently used in stroke research. Disabil Rehabil. 2006; 28: 1035-1040. PMid: 16950733. https : //doi.org/10.1080/09638280500494694

[37] William S, Sintler C, Pandyan A, et al. Is the practice of goal-setting for patients in acute stroke care patient-centred and what factors influence this? A qualitative study. Clinical Rehabilitation. 2016; 305(5): 508-519. 
[38] Struwe J, Baernholdt M, Noerholm V, et al. How is nursing care for stroke patients organised? Nurses' views on best practices. Journal of Nursing Management. 2013; 21: 141-151. PMid: 23339504. https://doi.org/10.1111/jonm.12016

[39] Feigin V, Roth G, Naghavi M, et al. Global burden of stroke and risk factors in 188 countries, during 1990-2013: A systematic analysis for the global burden of disease study. The Lancet Neurology. 2016; 15(9): 913-924. https://doi.org/10.1016/S1474-442 2 (16) 30073-4

[40] Watkins J. Clinical Guidelines for Stroke Management 2017. Melbourne Australia, National Manager Clinical Services, stroke foundation. 2017.

[41] Schmidt J, Fleming J, Ownsworth T, et al. Video feedback on functional task performance improves self-awareness after traumatic brain injury: a randomized controlled trial. Neuro rehabilitation and Neural Repair. 2013; 27: 316-24. PMid: 23270921. https://doi.org/10.1177/1545968312469838

[42] Schmitz M, Finkelstein M. Perspectives on post-stroke sexual issues and rehabilitation needs. Topics in Stroke Rehabilitation. 2010; 17: 204-213. PMid: 20797965. https ://doi .org/10.1310/tsr170 3-204

[43] Simmons-Mackie N, Raymer A, Armstrong E, et al. Communication partner training in aphasia: a systematic review. Archives of Physical Medicine \& Rehabilitation. 2010; 91: 1814-37. PMid: 21112422. https://doi.org/10.1016/j.apmr.2010.08.026

[44] Luu S, Lee AW, Daly A, et al. Visual field defects after stroke-a practical guide for GPs. Aust Fam Physician. 2010; 39: 499-503. PMid: 20628665.

[45] Slark J, Bentley P, Majeed A, et al. Awareness of stroke symptomatology and cardiovascular risk factors amongst stroke survivors. J. Stroke Cardiovasc Dis. 2012; 21: 358-62. PMid: 21111631. https://doi.org/10.1016/j.jstrokecerebrova sdis.2010.09.010

[46] Traynelis L. Emergency Department Nurses' Knowledge of EvidenceBased Ischemic Stroke Care. 2011; 10(1): 44

[47] Lawrence M, Kerr S, Watson H, et al. A survey of stroke nurses' knowledge of secondary prevention lifestyle issues: tobacco use, alcohol consumption, diet and physical activity. British Journal of Neuroscience Nursing. 2009; 5(11). https://doi .org/10.12968 /bjnn.2009.5.11.45148

[48] Johnson M, Cohn J, Bakas T. Emergency Department Nurses' Perceived Barriers and Facilitators to Caring for Stroke Patients. Journal of Neuroscience Nursing. 2011; 43(5). PMid: 21926517. https://doi.org/10.1097/JNN.0b013e318228e1cb

[49] Schneider A. Trends in community knowledge of warning signs and risk factors of stroke. The Journal of American Medical Mission. 2003; 289(3): 343-6. https://doi.org/10.1001/jama.289.3 .343

[50] Jouria J, Katz M. Comprehensive Acute Stroke Care. Wild Iris Medical Education, Inc.; 2013.

[51] Reynolds S, Murray L, McLennon S, et al. Implementation of a Stroke Competency Program to Improve Nurses' Knowledge of and Adherence to Stroke Guidelines. Journal of Neuroscience Nursing. 2016; 48: 328-332. PMid: 27602532. https ://doi.org/10.109 7/JNN. 0000000000000237

[52] Duffy J, Culp S, Yarberry C, et al. Nurses' research capacity and use of evidence in acute care: Baseline findings from a partnership study. Journal of Nursing Administration. 2015; 45(3): 158164. PMid: 25689502. https://doi.org/10.1097/NNA . 000000 0000000176

[53] Han J, Chen X. A Meta-Analysis of cigarette smoking prevalence among adolescents in China: 1981-2010. Int J Environ Res Public
Health. 2015; 12: 4617-30. PMid: 25922989. https://doi.org/ 10.3390/ijerph120504617

[54] Baker M. Education Requirements for Nurses Working with People with Complex Neurological Conditions: Nurses' Perceptions. Nurse Education Today. 2012; 41: 71-77. PMid: 21333416. https : //doi.org/10.1016/j.nedt.2011.01.011

[55] Long A, Kneafsey R, Ryan J, et al. The role of the nurse within the multidisciplinary team. Journal of Advanced Nursing. 2002; 37: 70 78. https ://doi.org/10.1046/j.1365-2648.2002.02059.x

[56] Elsayed I. Assessment of nurses' performance caring for patients with cerebrovascular stroke in intensive care unit. Master thesis. Faculty of nursing, Ain Shams University. Egypt. 2012.

[57] Whitehead M, Barton J. Passed Without a Stroke: A UK Mixed Method Study Exploring Student Nurses' Knowledge of Stroke. Nurse Education Today. 2013; 33: 998-1002. PMid: 22981516. https://doi.org/10.1016/j.nedt.2012.07.021

[58] Rowat A, Lawrence M, Horsburgh D, et al. Stroke research questions: A nursing perspective. Br. J. Nurs. 2009; 18(2): 100-5. PMid: 19270607. https://doi.org/10.12968/bjon.2009.18. 2.37862

[59] Islam S, Geum E, Wha Lee T, et al. Stroke Management Awareness and Behavior among Nursing Students in Bangladesh. Open Journal of Nursing. 2017; 7: 1-14. https://doi.org/10.4236/ojn. 20 17.71001

[60] Eldesouky E. Impact of an educational program for nurses' knowledge and practice about glasgow coma scale. International Journal of Recent Scientific Research. 2016; 7(3): 9690-9695, 9690.

[61] Subha P, Geethakumari S, Athira M, et al. Pattern and risk factors of stroke in the young among stroke patients admitted in medical college hospital. Annals of Indian Academy Neurology. 2015; 18(1): 2 .

[62] Zhang J, Wang Y, Wang G, et al. Clinical factors in patients with ischemic versus hemorrhagic stroke in East China. World Journal of Emergency Medicine. 2011; 2(1): 19. https://doi.org/10.584 7/wjem.j.1920-8642.2011.01.003

[63] AL-Abedi H, Hamza R. Self-Care Activities for Patients' with Stroke, International Journal of Scientific and Research Publications. 2016; 6(9): 530-536.

[64] Ali Z. Effect of Nursing Care Strategy on the Functional and Physical Abilities of Patients Following Stroke. Journal of Neurology \& Neurophysiology. 2013; 2-6.

[65] Sheean G. The pathophysiology of spasticity. Eur. J. Neurol. 2002; 1(3): 9-13. https://doi.org/10.1046/j.1468-1331.2002.0 090s1003.x

[66] Burneo J, Fang J, Saposnik G. Impact of seizures on morbidity and mortality after stroke. European Journal of Neurology. 2010; 17(1): 52-58. PMid: 19686350. https://doi.org/10.1111/j.1468-1 $331.2009 .02739 . x$

[67] Zaky H, Mohammad Z. Strategies of Daily Living Rehabilitative Activities for Post Stroke Patients at Minia University Hospital. Journal of Education and Practice. 2015; 6(5): 61-72.

[68] Kollen B, Lennon S, Lyons B, et al. The effectiveness of the Bobath concept in stroke rehabilitation: what is the evidence? Stroke. 2009; 40: 89-9. PMid: 19182079. https://doi.org/10.1161/STROKE AHA. 108.533828

[69] Debbie R, Janice J. Disparity between Functional Recovery and Daily Use of the Upper and Lower Extremities during Subacute Stroke Rehabilitation. Neurorehabil Neural Repair. 2012; 26: 76-84. PMid: 21693771. https://doi.org/10.1177/1545968311408918

[70] Lina B, Asa L, Christian B, et al. The Effects of a Rhythm and Music-Based Therapy Program and Therapeutic Riding in Late Recovery Phase following Stroke: a Study Protocol for a Three-armed 
Randomized Controlled Trial. BMC Neurology Journals. 2012; 141: [71] Stefan K, Stefan H, Peter O. Rehabilitation after Stroke. Neurologis1471-2377. che Rehabilitation Journal. 2011; 108: 600-606. 